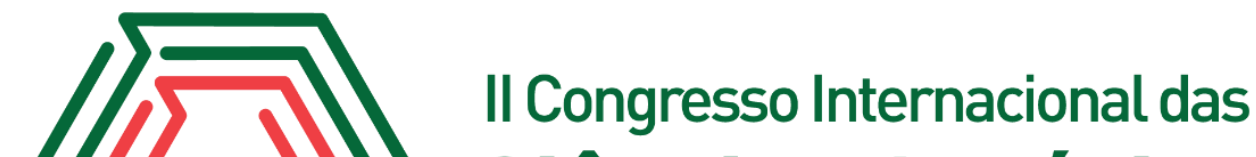 Ciências Agrárias COINTER - PDVAgro 2017
}

\section{USO DE RESÍDUOS ORGÂNICOS NA RECUPERAÇÃO DA FERTILIDADE DE ÁREAS DEGRADADAS}

\author{
Apresentação: Pôster
}

\begin{abstract}
Lucas de Sousa Oliveira ${ }^{1}$; Gustavo Henrique da Silva Albuquerque ${ }^{2} ;$ Luan Alves Lima ${ }^{3}$; Gemerson Machado de Oliveira ${ }^{4}$; Mirian Cristina Gomes Costa ${ }^{5}$
\end{abstract}

\section{Introdução}

O desmatamento, somado ao cultivo intensivo das terras sem adoção de práticas conservacionistas, resulta no declínio da fertilidade dos solos. A utilização de fertilizantes orgânicos e a adoção de praticas visando aumentar os teores de matéria orgânica no solo são fundamentais na melhoria dessa fertilidade.

Com o aumento nos custos dos fertilizantes minerais os crescentes níveis de poluição ambiental, a utilização adequada de resíduos orgânicos é uma alternativa para o suprimento de nutrientes como nitrogênio e fósforo em áreas de agricultura familiar no semiárido brasileiro. A reciclagem de resíduos oriundos das diversas cadeias produtivas, cuja deposição indevida pode causar impactos negativos ao ambiente, apresenta-se como importante alternativa para o uso de fertilizantes orgânicos.

Para recuperar solos degradados, uma prática promissora é a adição de resíduos orgânicos que trazem benefícios aos atributos físicos, químicos e biológicos. É importante que seja conhecida a composição desses resíduos, bem como seu potencial de liberação de nutrientes ao solo. No nordeste brasileiro são gerados resíduos como resíduos da agroindústria aviária, resíduo orgânico provenientes da produção e abate de pequenos ruminantes e resíduo da agroindústria processadora de goiabas.

O estudo parte da hipótese de que os resíduos anteriormente mencionados apresentam teores

\footnotetext{
${ }^{1}$ Doutorando em Ciência do Solo, Universidade Federal do Ceará, lucasdesousa@alu.ufc.br

${ }^{2}$ Doutorando em Ciência do Solo, Universidade Federal do Ceará, ghsa_rn@yahoo.com.br

${ }^{3}$ Mestrando em Ciência do Solo, Universidade Federal do Ceará, luanefa2@ yahoo.com.br

${ }^{4}$ Graduando em Agronomia, Universidade Federal da Paraíba, gemerson.oliveira@ hotmail.com

${ }^{5}$ Doutora, Universidade Federal do Ceará, mirian.costa@ufc.br
} 
de nutrientes que lhes conferem potencial de uso como adubos orgânicos. O objetivo neste estudo foi caracterizar os resíduos orgânicos e avaliar seu potencial como adubo orgânico de acordo com a Instrução Normativa DAS/MAPA 25/2009.

\section{Fundamentação Teórica}

O uso indiscriminado dos recursos naturais no semiárido, associado à características da região, acelera a degradação do solo. A redução do potencial produtivo de terras agrícolas tem sido atribuída às praticas de manejo inadequadas, o que torna o solo mais suscetível aos processos erosivos. Com o aumento dos processos erosivos há aumento das taxas de remoção de solos e nutrientes (SAHRAWAT, 2016).

Outro serio problema associado à degradação de solos é a redução no conteúdo de matéria orgânica com efeitos principalmente, sobre a CTC, disponibilidade de nutrientes, estabilidade de agregados e atividade microbiana. Além dos baixos teores de matéria orgânica, solos das regiões semiáridas são deficientes em outros nutrientes essenciais como o fósforo. Desta forma o uso combinado de fontes minerais e orgânicos é recomendado (SAHRAWAT, 2016).

No Brasil, são inúmeros os episódios críticos de poluição relacionados à ma disposição de resíduos, ocorrendo principalmente, a contaminação do solo e dos recursos hídricos por metais pesados e resíduos de defensivos agrícolas (CHACÓN et al., 2011).

Na agricultura realizada na região nordeste são utilizadas fontes orgânicas de nutrientes para realizar a adubação do solo, com destaque aos estercos provenientes da criação de animais, restos de culturas vegetais, como palhas e podas de leguminosas. Resíduos orgânicos possuem grande quantidade de nutrientes necessários as plantas, tais como nitrogênio, fosforo, cálcio, magnésio entre outros (ESSE et al., 2001), o manejo adequado desses resíduos pode ser evitada possíveis contaminações e imobilização de nutrientes disponíveis no solo (DUTRA et al., 2011).

A utilização desses resíduos como adubos orgânicos deve ser feita de forma criteriosa, pois se as quantidades adicionadas forem maiores que as requeridas pelas culturas, haverá acumulo de nutrientes no solo. Isso, em médio e longo prazos, pode prejudicar a qualidade dos solos, podendo ainda comprometer ecossistemas aquáticos (ABREU JUNIOR et al., 2012).

\section{Metodologia}

Os resíduos da agroindústria aviária e resíduo orgânico proveniente da produção e abate de pequenos ruminantes foi coletado de pilhas de compostagem e homogeneizados no momento da 
coleta para obter uma amostra composta uniforme. O resíduo da agroindústria processadora de goiabas o produto foi obtido após o processamento dos frutos sendo coletado uma amostra e homogeneizada no momento da coleta e coletado na quantidade de $600 \mathrm{~g}$ de cada um dos três resíduos avaliados no estudo. Posteriormente os resíduos foram secos em estufas de circulação de ar a $65^{\circ} \mathrm{C}$ por 48 horas e após a secagem foram realizados os procedimentos analíticos conforme o Manual de Métodos Analíticos Oficiais para Fertilizantes e Corretivos (MAPA).

\section{Resultados e Discussões}

Os resultados da composição química dos resíduos orgânicos estudados são apresentados na tabela 1 .

Tabela 1: Composição química dos resíduos orgânicos avaliados no estudo.

\begin{tabular}{cccc}
\hline Composição Química & T1 & T3 & T3 \\
\hline $\mathrm{pH}\left(\mathrm{CaCl}_{2}\right)$ & 6,1 & 6,4 & 6,8 \\
$\mathrm{Umidade} \mathrm{( \% )}$ & 6,6 & 6,4 & 9,8 \\
$\mathrm{~N}\left(\mathrm{~g} \mathrm{~kg}^{-1}\right)$ & 29,8 & 14,8 & 26,7 \\
$\mathrm{CO}\left(\mathrm{g} \mathrm{kg}^{-1}\right)$ & 145,1 & 157,2 & 162,9 \\
$\mathrm{P}\left(\mathrm{g} \mathrm{kg}^{-1}\right)$ & 7,6 & 8,3 & 1,4 \\
$\mathrm{~K}\left(\mathrm{~g} \mathrm{~kg}^{-1}\right)$ & 20,2 & 1,9 & 2,6 \\
$\mathrm{Ca}\left(\mathrm{g} \mathrm{kg}^{-1}\right)$ & 8,7 & 20,3 & 4,2 \\
$\mathrm{Mg}\left(\mathrm{g} \mathrm{kg}^{-1}\right)$ & 1,2 & 7,5 & 0,4 \\
$\mathrm{Na}\left(\mathrm{g} \mathrm{kg}^{-1}\right)$ & 2,5 & 3,5 & 0,2 \\
$\mathrm{~S}\left(\mathrm{~g} \mathrm{~kg}^{-1}\right)$ & 1,2 & 1,3 & 2,2 \\
$\mathrm{Cu}\left(\mathrm{mg} \mathrm{kg}^{-1}\right)$ & 0,1 & 0,3 & 0,1 \\
$\mathrm{Fe}\left(\mathrm{mg} \mathrm{kg}^{-1}\right)$ & 7,3 & 53,4 & 7,6 \\
$\mathrm{Mn}\left(\mathrm{mg} \mathrm{kg}^{-1}\right)$ & 1,5 & 3,5 & 1,1 \\
$\mathrm{Zn}\left(\mathrm{mg} \mathrm{kg}^{-1}\right)$ & 0,6 & 2 & 0,6 \\
\hline
\end{tabular}

T1- resíduo da agroindústria aviária; T2- resíduo orgânico produzido com resíduos de pequenos ruminantes e T5resíduo da agroindústria processadora de goiabas. "Teores dos elementos químicos com base na matéria seca dos materiais analisados.

Os materiais analisados apresentaram variações nos valores dos atributos avaliados para sua caracterização, o que é explicado pelas diferentes origens dos resíduos orgânicos estudados. A análise da composição química dos resíduos orgânicos expôs a capacidade dos mesmos em contribuir com a nutrição de plantas e recuperação da fertilidade de solos degradados. De acordo com a Instrução Normativa DAS/MAPA 25/2009 os resíduos resíduo da agroindústria aviária (T1), resíduo orgânico produzido com resíduos de pequenos ruminantes (T2) e resíduo da agroindústria processadora de goiabas (T3) apresentam teores de nutrientes que permitem que os mesmos sejam usados como adubos orgânicos. 
Teores elevados de $\mathrm{N}$ total em resíduos orgânicos pode ser um indicativo que estes poderão atuar como fonte imediata de $\mathrm{N}$ para as plantas (BARRAL et al., 2011). O tratamento $\mathrm{T} 1$ apresentou o maior teor de nitrogênio, dessa forma espera-se que a mineralização desse nutriente seja elevada pela baixa relação $\mathrm{C} / \mathrm{N}$.

O teor de $\mathrm{P}$ do resíduo da agroindústria aviária foi inferior ao obtido por Nascimento et al. (2015) e semelhante ao teor encontrado por Souza et al. (2016) ao avaliar o composto orgânico produzido com resíduo de pequenos ruminantes na produção de milho. Desse modo, os resíduos da agroindústria aviária e o composto orgânico produzido com resíduos de pequenos ruminantes podem ser utilizados como fontes alternativas complementares de fósforo para o solo, especialmente em solos da região semiárida que, na sua maioria, apresentam baixos níveis desse nutriente (SOUTO et al., 2013).

Quanto aos metais $\mathrm{Cu}, \mathrm{Fe}, \mathrm{Zn}$ e $\mathrm{Mn}$ os teores obtidos com a caracterização química evidenciam que tais resíduos orgânicos não trazem preocupação de contaminação do ambiente. Porém, mesmo em quantidades que sejam permitidas pela legislação deve-se ter monitoramento da aplicação de resíduos orgânicos, pois, em pequenas concentrações, mili ou microgramas, esses metais em alguns casos podem provocar efeitos danosos ao ambiente (SANTOS et al., 2014).

\section{Conclusões}

A partir dos resultados da caracterização química dos resíduos orgânicos aceita-se a hipótese de que os resíduos orgânicos estudados apresentam teores de nutrientes que lhes conferem potencial de uso como adubos orgânicos de acordo com a Instrução Normativa DAS/MAPA 25/2009.

\section{Referências}

ABREU JUNIOR, C. H.; MURAOKA, T.; OLIVEIRA, F. C.; Carbono, nitrogênio, fosforo e enxofre em solos tratados com composto de lixo urbano. Revista Brasileira de Ciência do Solo, v. 26, p. 769-780, 2012.

BRASIL. Ministério da Agricultura, Pecuária e Abastecimento. Instrução Normativa $\mathrm{n}^{\circ}$ 8, de 25 de março de 2004. Proíbe em todo o território nacional a produção, a comercialização e a utilização de produtos destinados à alimentação de ruminantes que contenham em sua composição proteínas e gorduras de origem animal. Diário Oficial da República Federativa do Brasil, Brasília, DF, 14 jul. 2004. Seção 1, p. 5.

CHACÓN, E. A. V.; MENDONÇA, E. S.; SILVA, R. R.; LIMA, P. C.; SILVA, I. V.; CANTARUTTI, R. B. Decomposição de fontes orgânicas e mineralização de forma de nitrogênio e fosforo. Revista Ceres, v. 58, p. 373-383, 2011. 
DUTRA, E. D.; MENEZES, R. S. C.; PRIMO, D. C. Aproveitamento de biomassa residual agrícola para a produção de compostos orgânicos. Revista Brasileira de Ciências Agrárias, v. 7, p. 465$472,2011$.

NASCIMENTO, C. D. V.; PONTES FILHO, R. A.; ARTUR, A. G.; COSTA, M. C. G. Application of poultry processing industry waste: A strategy for vegetation growth in degraded soil. Waste Management, v. 36, p. 316-322, 2015.

SAHRAWAT, K. L. How fertile are semi-arid tropical soils? Soil and Water Management, v. 110, p. 1671-1674, 2016.

SANTOS, A. T. L.; HNERIQUE, N. S.; SHHLINDWEIN, J. A.; FERREIRA, E.; STACHIW, R. Aproveitamento da fração orgânica dos resíduos sólidos urbanos para produção de composto orgânico. Revista Brasileira de Ciências da Amazônia, v. 3, p. 15-28, 2014.

SOUTO, P. C.; SOUTO, J. S.; NASCIMENTO, J. A. M. Liberação de nutrientes de estercos em Luvissolo no semiárido paraibano. Revista Caatinga, v. 26, p. 69-78, 2013.

SOUZA, N. G. M.; SILVA, J. A.; MAIA, J. M.; SILVA, J. B.; NUNES JÚNIOR, E. S.; MENESES, C. H. S. G. Tecnologias sociais voltadas para o desenvolvimento do semiárido brasileiro. Revista Biofarm, v. 12, p. 1-12, 2016. 